\title{
RESEARCH
}

Open Access

\section{State of the psychometric methods: patient-reported outcome measure development and refinement using item response theory}

\author{
Angela M. Stover ${ }^{1,2}$, Lori D. McLeod ${ }^{3 *}$, Michelle M. Langer ${ }^{2,4}$, Wen-Hung Chen ${ }^{3}$ and Bryce B. Reeve $e^{1,5}$
}

\begin{abstract}
Background: This paper is part of a series comparing different psychometric approaches to evaluate patient-reported outcome (PRO) measures using the same items and dataset. We provide an overview and example application to demonstrate 1) using item response theory (IRT) to identify poor and well performing items; 2) testing if items perform differently based on demographic characteristics (differential item functioning, DIF); and 3) balancing IRT and content validity considerations to select items for short forms.

Methods: Model fit, local dependence, and DIF were examined for 51 items initially considered for the Patient-Reported Outcomes Measurement Information System ${ }^{\oplus}$ (PROMIS ${ }^{\oplus}$ ) Depression item bank. Samejima's graded response model was used to examine how well each item measured severity levels of depression and how well it distinguished between individuals with high and low levels of depression. Two short forms were constructed based on psychometric properties and consensus discussions with instrument developers, including psychometricians and content experts. Calibrations presented here are for didactic purposes and are not intended to replace official PROMIS parameters or to be used for research.

Results: Of the 51 depression items, 14 exhibited local dependence, 3 exhibited DIF for gender, and 9 exhibited misfit, and these items were removed from consideration for short forms. Short form 1 prioritized content, and thus items were chosen to meet DSM-V criteria rather than being discarded for lower discrimination parameters. Short form 2 prioritized well performing items, and thus fewer DSM-V criteria were satisfied. Short forms 1-2 performed similarly for model fit statistics, but short form 2 provided greater item precision.

Conclusions: IRT is a family of flexible models providing item- and scale-level information, making it a powerful tool for scale construction and refinement. Strengths of IRT models include placing respondents and items on the same metric, testing DIF across demographic or clinical subgroups, and facilitating creation of targeted short forms. Limitations include large sample sizes to obtain stable item parameters, and necessary familiarity with measurement methods to interpret results. Combining psychometric data with stakeholder input (including people with lived experiences of the health condition and clinicians) is highly recommended for scale development and evaluation.
\end{abstract}

Keywords: Item response theory, Scale construction, Scale evaluation, Measurement, PROMIS ${ }^{\oplus}$

\footnotetext{
* Correspondence: Imcleod@rti.org

${ }^{3}$ RTI Health Solutions, 3040 Cornwallis Road, Research Triangle Park, NC

27709-2194, USA

Full list of author information is available at the end of the article
} 


\section{Background}

Patient-reported outcome (PRO) measures quantify the impact of health conditions and treatments on people's lives with respect to how they feel, function, and perceive their health-related quality of life [1]. PROs are routinely used to inform clinical trial endpoints (see [2-4]) and are increasingly used in drug labeling claims $[1,5,6]$. In routine care, systematically administered PROs improve detection of symptoms, and enhance clinician-patient communication and patients' satisfaction with care [7-10]. Given this variety of uses, robust PRO measure development and evaluation is critical. Initiatives such as the Patient-Reported Outcomes Measurement Information System $^{\odot} \quad\left(\right.$ PROMIS $\left.^{\oplus}\right) \quad[11,12]$ and the European Organization for Research and Treatment of Cancer (EORTC) $[13,14]$ are examples of international programs leading PRO measure development.

Psychometric theory and its statistical models play an important role in developing and evaluating PRO measures. For example, there is a large literature on applying statistical methods such as item response theory (IRT) to develop and evaluate PRO measures (e.g., [15-20]). However, little PRO literature is available directly comparing different psychometric approaches and content considerations. This paper is part of a series comparing psychometric approaches (IRT, classical test theory, and Rasch analysis) using the same items and dataset [21].

The objective of the current paper is to provide an overview and example application demonstrating how IRT and content validity considerations can be used to develop and refine PRO measures. Description of an example software application (IRTPRO) and sample output are provided [22]. IRT methodology is applied to 51 items considered for the initial PROMIS Depression item bank [23] that were tested as part of wave 1 testing $[11,12]$. The official PROMIS ${ }^{\oplus}$ Depression item bank has a subset of 28 items because items with psychometric or content issues were eliminated [11, 12, 23, 24]. The larger Depression item bank of 51 items was chosen for the current paper so there would be more opportunities to identify problematic psychometric issues. We demonstrate: 1) using IRT to identify poor and well performing items; 2) testing if items perform differently based on demographic characteristics (using differential item functioning [DIF] testing); and 3) balancing IRT and content validity considerations to select items for short forms.

The PROMIS $^{\circledast}$ system includes several versions of Depression short forms including a subset of items from the 28-item calibrated bank [23]. For this paper, we purposely created new short forms based at least in part on the Diagnostic and Statistical Manual version 5 (DSM-V) [25] to avoid duplication with prior work. The calibrations and short forms presented in this series are for didactic purposes and are not intended to be used for research or to replace official PROMIS ${ }^{\bullet}$ versions (see www.healthmeasures.net).

\section{IRT overview}

IRT is a family of statistical models providing information about the performance of items and the scales they comprise through the analysis of item responses. IRT has been widely used in the education field for over 40 years and is increasingly used to develop and evaluate PRO measures. Unidimensional (single factor) and multi-dimensional (more than one factor) IRT models are available but this paper focuses on unidimensional IRT models. Readers interested in multidimensional IRT are referred to these sources [26, 27].

IRT-calibrated item banks (such as PROMIS) offer multiple options for instrument development and refinement, including creating customized short forms comprised of a fixed set of items or administering a tailored assessment through computerized adaptive testing (CAT). Because items are linked (or calibrated) by the IRT model, scores can be compared across administrations or different samples using IRT scaling. IRT-derived scores typically are more sensitive in cross-sectional tests and are more responsive to changes in health over time than scores for the same item set produced using classical methods [19].

IRT models are mathematical equations that describe the relationship between the latent trait being measured (commonly denoted as theta: $\theta$ ), such as depression level, and the probability of endorsing a given response to an item that serves as an indicator of the trait being measured. A popular IRT model used in PRO research is Samejima's [28, 29] graded response model (GRM), which can be used when there are three or more response choices for each item within the PRO measure. In the current example, the PROMIS ${ }^{\oplus}$ Depression items have five response options (never, rarely, sometimes, often, always) to measure frequency of depression symptoms.

A helpful feature of IRT is the ability to produce visual images of how well items are performing. Item characteristic curves (ICCs) or "trace lines" [30] visually depict the relationship between the probability of item responses and $\theta$. In graphical form, ICCs display arcs or curves for each response option on the same graph. Figure 1 is an example of ICCs for an item with five response options. The vertical axis of the ICC graph represents the probability of endorsement and the horizontal axis is $\theta$ (depression level). By convention, the $\theta$ metric is standardized to a mean of 0 and standard deviation of 1 , but can be converted to any metric using a linear transformation. ICCs are valuable for determining the appropriate number of response categories based on patients' responses and the latent trait level that an individual likely has in order to endorse each response option. Additionally, both items and individuals can 


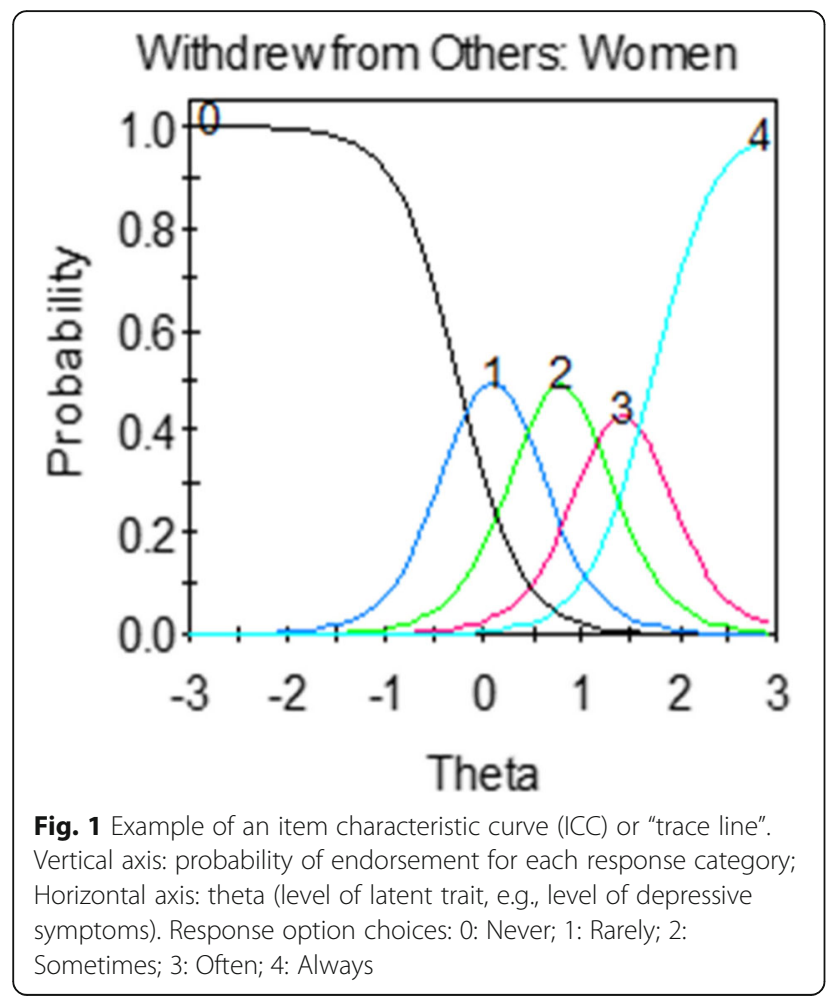

be characterized on a common metric along the latent trait continuum.

Graphical representations of ICCs are derived from a formula. In the GRM, the formula for ICCs (trace lines) is:

$$
P\left(x_{i}=j \mid \theta\right)=\frac{1}{1+\exp \left[-a_{i}\left(\theta-b_{i j}\right)\right]}-\frac{1}{1+\exp \left[-a_{i}\left(\theta-b_{i j+1}\right)\right]},
$$

which states that the probability of responding in category $j$ (e.g., response option of "rarely") is the difference between trace lines for the probability of responding in category $j$ or higher and category $j+1$ or higher. In the formula, $a_{i}$ is the item slope (or discrimination) parameter and $b_{i j}$ are the item threshold (or severity) parameters [31]. The slope parameter $(a)$ measures the strength of the relationship between the item and $\theta$.

Values of $a$ range from 0 to infinity, where higher slopes indicate that the item discriminates more sharply between individuals above and below a particular value of $b$. For example, depression items with larger slopes are better able to distinguish between individuals with higher and lower levels of depression.

Threshold parameters $\left(b_{i j}\right)$ represent the points along the latent trait at which a respondent whose $\theta=b_{i j}$ has a 0.5 probability of selecting response option $j$ or higher. The higher the $b$-parameters, the higher the trait level a respondent needs to have in order to endorse that response option.
The GRM produces $C-1$ estimated $b$-parameters, where $C$ is the number of response options. For an item with five response categories (common in PROs), there are four thresholds $\left(b_{1}-b_{4}\right) \cdot b_{1}$ is the threshold for the trace line describing the probability of selecting response options 1 , 2,3 , or $4 ; b_{2}$ is for response options 2,3 , or $4 ; b_{3}$ is for response options 3 or 4 ; and $b_{4}$ is for response option 4 . Values of $b$-parameters typically range from -3 to +3 and are interpreted as standard deviations showing the range of $\theta$ (depression level) covered by the item. For example, if $b_{1}$ is 0 and $b_{4}$ is 3 , the item provides the most information about depression from the mean to three standard deviations above the mean. Table 1 provides an overview of key concepts used in IRT. Readers interested in the statistical underpinnings of IRT are referred to [17, 32].

\section{Unidimensional IRT model assumptions}

Unidimensional IRT models have four major assumptions: one dominant factor exists across the measure; items are locally independent; monotonicity; and modeldata fit [15-20]. Unidimensionality indicates that the set of items assesses a single underlying trait. One paper in this series [33] conducted extensive analyses confirming that the PROMIS ${ }^{\circ}$ depression items are unidimensional.

Local independence indicates each item is contributing uniquely to the latent trait being measured. Two items are said to be locally dependent if they contain extra association (co-variance) beyond what is measured by the latent trait. Model-data fit includes overall fit and individual item is fit for the specified IRT model [32]. Related to model-data fit, monotonicity is also assumed, indicating that the probability of endorsing response options indicative of higher levels of the measured trait (e.g., depression) increases with an individual's level of the latent trait.

When a set of items satisfies the assumptions of one dominant factor, local independence, monotonicity, and modeldata fit, the latent trait estimates are independent of the specific item set, and the item parameters are independent of the sample; these properties are a major advantage of IRT.

\section{Methods \\ Item pool}

The US National Institutes of Health (NIH)-funded PROMIS initiative developed item banks assessing common symptoms using state-of-the-art scale development methods [23, 34-36]. For the PROMIS Depression item bank used in this didactic example, an initial item pool consisting of over 500 items from more than 100 depression measures (proprietary measures were removed) were reviewed by clinical and measurement experts [23]. Focus groups were conducted with patients to enrich the item pool [35]. Items were categorized according to a priori depression subdomains of affect, cognition, behavioral (e.g., social withdrawal), somatic (e.g., sleep, weight), 
Table 1 Common terms used in an IRT graded response model

\begin{tabular}{|c|c|c|}
\hline Term & $\begin{array}{l}\text { Abbreviation/ } \\
\text { Symbol }\end{array}$ & Description \\
\hline $\begin{array}{l}\text { Slope } \\
\text { parameter }\end{array}$ & $a$ & $\begin{array}{l}\text { - Also referred to as the discrimination } \\
\text { parameter. } \\
\text { - Measures the strength of the } \\
\text { relationship between the item and } \\
\text { the latent variable being measured. } \\
\text { - Items with larger slopes are better } \\
\text { able to distinguish between individuals } \\
\text { with higher and lower levels of the } \\
\text { latent variable being measured. }\end{array}$ \\
\hline $\begin{array}{l}\text { Threshold } \\
\text { parameters }\end{array}$ & $b_{i j}$ & $\begin{array}{l}\text { - Also known as the location parameters } \\
\text { or the difficulty/severity parameters. } \\
\text { - Represents the points along theta at } \\
\text { which the corresponding response } \\
\text { categories are the most discriminating } \\
\text { or informative. } \\
\text { - Items with higher thresholds represent } \\
\text { greater severity of the latent variable } \\
\text { being measured. }\end{array}$ \\
\hline Theta & $\Theta$ & $\begin{array}{l}\text { - Latent variable being measured } \\
\text { (e.g., depression). }\end{array}$ \\
\hline $\begin{array}{l}\text { Item } \\
\text { characteristic } \\
\text { curve }\end{array}$ & $\mathrm{ICC}$ & $\begin{array}{l}\text { - Also referred to as a "trace line." } \\
\text { - Visual image showing the probability } \\
\text { of an item response across the range } \\
\text { of theta (latent trait). } \\
\text { - Can reveal weak items and } \\
\text { overlapping response categories. }\end{array}$ \\
\hline $\begin{array}{l}\text { Test } \\
\text { characteristic } \\
\text { curve }\end{array}$ & TCC & $\begin{array}{l}\text { - Sum of the ICCs across all items. } \\
\text { - Shows the expected total summed } \\
\text { score on the scale for each level of } \\
\text { theta. }\end{array}$ \\
\hline $\begin{array}{l}\text { Item } \\
\text { information } \\
\text { function }\end{array}$ & $\| F$ & $\begin{array}{l}\text { - Index of the precision in measurement } \\
\text { in distinguishing between individuals } \\
\text { with different levels of the latent } \\
\text { variable being measured. } \\
\text { - More information indicates greater } \\
\text { precision and reliability. } \\
\text { - Item information is peaked when the } \\
\text { slope parameter is high. } \\
\text { - Standard error of measurement is } \\
\text { inversely related to information. }\end{array}$ \\
\hline $\begin{array}{l}\text { Test } \\
\text { information } \\
\text { function }\end{array}$ & $\mathrm{TIF}$ & $\begin{array}{l}\text { - Sum of the item information functions } \\
\text { across all items. } \\
\text { - Indicates where along theta the scale } \\
\text { has the greatest measurement } \\
\text { precision. }\end{array}$ \\
\hline Item fit & $S-X^{2}$ & $\begin{array}{l}\text { - Diagnostic statistic that examines } \\
\text { goodness of fit of the IRT model for } \\
\text { each item. } \\
\text { - Examines observed and expected } \\
\text { response proportions for each item } \\
\text { value. } \\
\text { - Significant result indicates item misfit. }\end{array}$ \\
\hline $\begin{array}{l}\text { Local } \\
\text { dependence }\end{array}$ & LD & $\begin{array}{l}\text { - Statistic that examines bivariate fit to } \\
\text { identify evidence of items that are } \\
\text { excessively related given the common } \\
\text { underlying construct. } \\
\text { - Significant result indicates content } \\
\text { redundancy between two or more } \\
\text { items. }\end{array}$ \\
\hline $\begin{array}{l}\text { Differential } \\
\text { item functioning }\end{array}$ & DIF & $\begin{array}{l}\text { - Measurement bias in an item between } \\
\text { two or more groups while holding } \\
\text { the latent trait level constant. }\end{array}$ \\
\hline
\end{tabular}

and suicidal ideation. Items judged to best represent each category were rewritten into a common format with a 7-day recall period. Three rounds of cognitive interviews were conducted with patients to ensure comprehensibility [36] before field testing the item bank. One item uses an intensity response scale (I lost weight without trying: "not at all," "a little," "somewhat," "quite a bit," "very much"), and the remaining 50 items use a frequency response scale ("never," "rarely," "sometimes," "often," "always").

The current analyses use data for 51 items initially considered for inclusion in the PROMIS Depression item bank (28 items appear in the official calibrated bank) [23]. We used the larger item set as a didactic exercise to identify psychometric issues using IRT. The calibrations and short forms presented in this paper are not intended to replace official PROMIS parameters or to be used for research purposes. For instance, the parameters presented in the current paper have not been converted to a T-score metric centered on a censusmatched sample like the PROMIS ${ }^{\oplus}$ Depression item bank. Additionally, we also used a different content criterion (DSM-V) than the original paper (affective and cognitive dimensions of depression [23]). For the current paper, IRB exemption was granted from the University of North Carolina at Chapel Hill.

\section{Overview of IRTPRO software}

IRTPRO software [22] was used to examine model fit, local independence, and DIF (see Fig. 2 for screen shots on how to run and interpret DIF). The user-interface is Windows-based, meaning that users "point and click" to invoke default settings for models but also have the flexibility to manually impose constraints on any parameter. IRTPRO offers a range of model choices, including: unidimensional and multidimensional models; one-, two-, and three-parameter logistic models [31, 37]; Samejima's graded response model [28, 29]; generalized partial credit model [38, 39]; and the nominal response model [40, 41].

The default setting in IRTPRO for item parameter estimation/calibration is maximum likelihood [22] and we used the default. The default setting can be changed by specifying prior distributions for item parameters (in which case maximum a posteriori estimates would be computed) [22].

\section{Short-form development methods}

A goal of this paper is to demonstrate the design of unidimensional short forms using a combination of IRT and content validity considerations. Content validity is the extent to which an item bank or short form captures key aspects of the concept it is supposed to measure. Two potential short forms were generated by consensus discussions conducted with psychometricians and content 


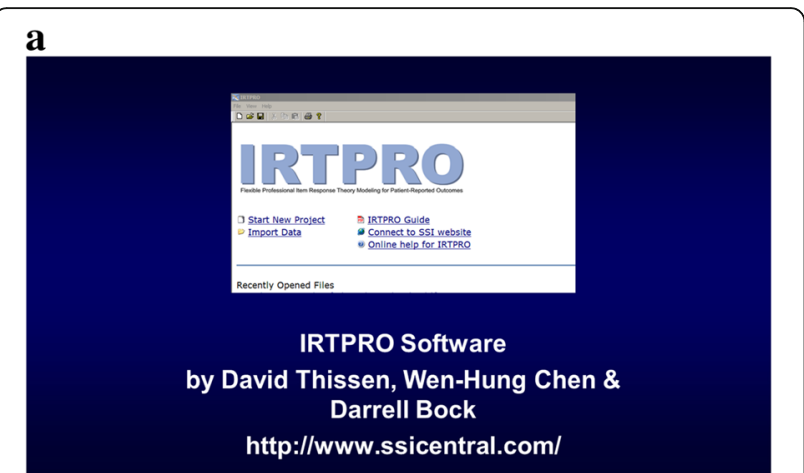

b

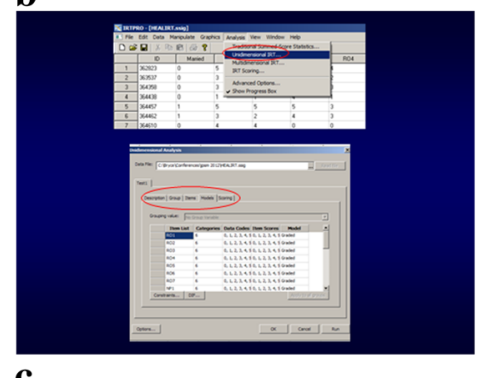

c

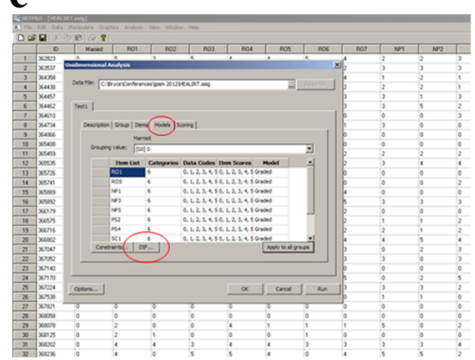

d

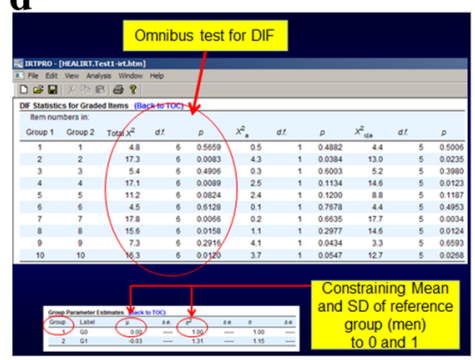

Fig. 2 IRTPRO screen shots for graded response model and differential item functioning. $\mathbf{a}$ introductory screen. $\mathbf{b}$ first part of sequence to enable DIF detection c second part of sequence to enable DIF d DIF Output

experts. Short form 1 prioritized items assessing DSM-V criteria for major depression: 1) depressed mood most of the day, every day, or markedly diminished interest or pleasure in activities; 2) at least five types of symptoms (significant weight gain or loss/appetite loss, insomnia/ hypersomnia, psychomotor agitation or retardation, fatigue, worthlessness/excessive guilt, diminished ability to think/concentrate or indecisiveness, or suicidal ideation); and 3) clinically significant distress or impairment in social, occupational, or other areas [25]. Short form 2 prioritized well performing items in Table 2 (based on $a$ - and $b$-parameters).

We compared model fit statistics for two short forms and the original bank of 51 depression items. Model fit statistics quantify the discrepancy between observed and expected values for model-data fit. We used conventional fit criteria [42] including the model fit statistic, $\mathrm{M}_{2}$, [43, 44], Akaike information criterion (AIC) [45], Bayesian information criterion (BIC) [46], and root mean square error of approximation (RMSEA). A significant result for the model fit statistic $\left(\mathrm{M}_{2}\right)$ indicates that the model does not fit the data (i.e., the null hypothesis is a correctly specified model). $\mathrm{M}_{2}$ can be sensitive if dimensionality is incorrectly specified [42]. AIC and BIC are appropriate when maximum likelihood estimation has been used (as in our example). In practice, BIC imposes a stronger penalty than AIC when models are complex. RMSEA adjusts for sample size. For AIC, BIC, and RMSEA lower numbers indicate better fit (significance tests are not possible but they do provide estimates of relative differences between solutions). See [42] for a description of pros and cons for goodness of fit statistics for IRT models. Stone [47] and Cai [48] also describe alternative approaches to assessing IRT model-data-fit.

In addition to model fit, a diagnostic statistic $\left(S-X^{2}\right)$ $[49,50]$ was used to examine item-level goodness of fit. $S-X^{2}$ compares observed and expected response proportions for each item value. We used a significance value of 0.01 to correct for multiple tests [51]. Readers interested in a discussion of common approaches to the multiplicity problem and a discussion of alternatives are referred to $[51,52]$.

\section{Local independence}

Local dependence (LD) indicates there is excessive covariance between two or more items. The LD statistic [53] examines bivariate fit to identify items that are excessively related after accounting for the latent trait. These diagnostic statistics are approximately standardized $X^{2}$ values that become large (10 or higher) if a pair of items violates local independence. Borderline values between 5 and 10 may indicate local dependence or they may be a result of sparseness in one or more response categories. Consensus discussions among psychometricians and content experts are highly recommended to help determine content redundancy.

\section{Differential item functioning}

Differential item functioning (DIF) is the detection of items performing differently in subgroups (e.g., men and women) when the latent trait level (depression) is held constant [54]. DIF is important to consider because it can be a threat to validity if members from subgroups 
Table 2 Item parameters, fit statistics, local dependence, and DIF results for the 51 PROMIS ${ }^{\oplus}$ depression items

\begin{tabular}{|c|c|c|c|c|c|c|c|c|c|c|c|}
\hline \multirow[t]{2}{*}{$\#$} & \multirow[t]{2}{*}{ Item Stem } & \multicolumn{5}{|c|}{ Item Parameters } & \multicolumn{2}{|c|}{ Item Fit } & \multirow[b]{2}{*}{ LD } & \multicolumn{2}{|c|}{$b$-DIF } \\
\hline & & $a$ & $b_{1}$ & $b_{2}$ & $b_{3}$ & $b_{4}$ & $\overline{S-X^{2}}$ & d.f. & & $\overline{x^{2}}$ & d.f. \\
\hline 1 & I felt hopeless & 4.46 & 0.38 & 0.97 & 1.53 & 2.23 & 116.2 & 88 & & & \\
\hline 2 & I felt worthless & 4.17 & 0.44 & 1.00 & 1.57 & 2.14 & 102.0 & 91 & & & \\
\hline 3 & I felt depressed & 3.84 & -0.11 & 0.59 & 1.29 & 2.15 & 163.4 & 120 & & & \\
\hline 4 & I felt unhappy & 3.81 & -0.39 & 0.41 & 1.27 & 2.06 & 151.5 & 120 & & & \\
\hline 5 & I felt that nothing could cheer me up & 3.73 & 0.32 & 0.94 & 1.73 & 2.34 & 99.4 & 98 & & & \\
\hline 6 & I felt like a failure & 3.73 & 0.19 & 0.72 & 1.58 & 2.05 & 137.2 & 116 & & & \\
\hline 7 & I felt helpless & 3.65 & 0.35 & 0.94 & 1.67 & 2.36 & 115.0 & 105 & & & \\
\hline 8 & I felt that I wanted to give up on everything & 3.6 & 0.56 & 1.1 & 1.6 & 2.3 & 111.3 & 95 & & & \\
\hline 9 & I felt that I had nothing to look forward to & 3.3 & 0.31 & 0.8 & 1.5 & 2.3 & 147.1 & 117 & & & \\
\hline 10 & I felt that my life was empty & 3.24 & 0.28 & 0.73 & 1.56 & 2.11 & 148.5 & 120 & & & \\
\hline 11 & I felt emotionally exhausted & 3.32 & -0.18 & 0.49 & 1.27 & 2.05 & 126.0 & 133 & & & \\
\hline 12 & I felt sad & 3.20 & -0.47 & 0.37 & 1.31 & 2.29 & 205.7 & 131 & & & \\
\hline 13 & I felt I had no reason for living & 3.1 & 0.92 & 1.5 & 1.9 & 2.6 & 83.2 & 71 & $21,29,35$ & & \\
\hline 14 & I found that things in my life were overwhelming & 3.1 & -0.09 & 0.6 & 1.5 & 2.3 & 153.8 & 138 & & & \\
\hline 15 & I felt that I was not needed & 3.08 & 0.21 & 0.84 & 1.55 & 2.38 & 162.4 & 127 & & & \\
\hline 16 & I felt disappointed in myself & 3.05 & -0.35 & 0.39 & 1.31 & 2.09 & 199.9 & 146 & & & \\
\hline 17 & I felt like I needed help for my depression & 3.0 & 0.54 & 1.01 & 1.7 & 2.2 & 150.2 & 105 & & & \\
\hline 18 & I had trouble enjoying the things I used to enjoy & 2.9 & -0.09 & 0.60 & 1.4 & 2.2 & 165.2 & 146 & & & \\
\hline 19 & I felt discouraged about the future & 2.92 & -0.26 & 0.37 & 1.31 & 2.09 & 159.4 & 153 & & & \\
\hline 20 & I felt that I was to blame for things & 2.88 & -0.02 & 0.73 & 1.63 & 2.38 & 181.3 & 141 & & & \\
\hline 21 & I wished I were dead and away from it all & 2.8 & 1.01 & 1.5 & 2.1 & 2.6 & 103.3 & 71 & $13,29,35$ & & \\
\hline 22 & I felt upset for no reason & 2.83 & 0.23 & 0.93 & 1.85 & 2.93 & 135.3 & 117 & & & \\
\hline 23 & I felt that nothing was interesting & 2.83 & 0.06 & 0.87 & 1.90 & 2.64 & 122.1 & 122 & & & \\
\hline 24 & I felt I was not as good as other people & 2.8 & 0.15 & 0.80 & 1.6 & 2.3 & 161.5 & 130 & & & \\
\hline 25 & I withdrew from other people & 2.72 & 0.04 & 0.70 & 1.47 & 2.30 & 160.5 & 144 & & & \\
\hline 26 & I had trouble making decisions & 2.71 & -0.16 & 0.75 & 1.66 & 2.57 & 174.8 & 140 & 32,38 & & \\
\hline 27 & I had trouble feeling close to people & 2.66 & -0.12 & 0.55 & 1.41 & 2.24 & 153.6 & 155 & & & \\
\hline 28 & I felt pessimistic & 2.65 & -0.30 & 0.48 & 1.38 & 2.23 & 198.8 & 155 & & & \\
\hline 29 & I felt that others would be better off if I were dead & 2.6 & 1.10 & 1.55 & 2.4 & 3.0 & 70.1 & 67 & $13,21,35$ & & \\
\hline 30 & I felt lonely & 2.54 & -0.09 & 0.60 & 1.45 & 2.21 & 186.0 & 158 & & & \\
\hline 31 & I felt unloved & 2.51 & 0.26 & 0.90 & 1.76 & 2.48 & 161.8 & 136 & & & \\
\hline 32 & I had trouble thinking clearly & 2.51 & -0.15 & 0.78 & 1.84 & 2.84 & 178.7 & 145 & 26,38 & & \\
\hline 33 & I had mood swings & 2.45 & -0.32 & 0.56 & 1.42 & 2.32 & 181.8 & 153 & & & \\
\hline 34 & I felt like crying & 2.44 & 0.05 & 0.82 & 1.67 & 2.62 & 178.5 & 148 & 45 & 43.4 & 4 \\
\hline 35 & I thought about suicide & 2.43 & 1.34 & 1.80 & 2.37 & 2.86 & 74.9 & 54 & $13,21,29$ & & \\
\hline 36 & I felt ignored by people & 2.41 & -0.07 & 0.73 & 1.67 & 2.55 & 190.2 & 150 & & & \\
\hline 37 & I felt guilty & 2.39 & 0.07 & 0.86 & 1.76 & 2.54 & 160.8 & 139 & & & \\
\hline 38 & I had trouble keeping my mind on what I was doing & 2.4 & -0.47 & 0.45 & 1.7 & 2.7 & 187.6 & 152 & 26,32 & & \\
\hline 39 & I felt that everything I did was an effort & 2.3 & -0.21 & 0.60 & 1.5 & 2.4 & 181.3 & 165 & & & \\
\hline 40 & My thinking was slower than usual & 2.12 & -0.22 & 0.78 & 2.09 & 3.11 & 155.6 & 139 & 46 & & \\
\hline 41 & I felt slowed down & 2.09 & -0.48 & 0.38 & 1.47 & 2.55 & 226.9 & 168 & 43,44 & & \\
\hline 42 & I felt like being alone & 1.99 & -0.83 & -0.19 & 1.09 & 2.37 & 214.8 & 172 & & & \\
\hline 43 & I got tired more easily than usual & 1.99 & -0.56 & 0.24 & 1.37 & 2.39 & 216.3 & 182 & 41,44 & & \\
\hline
\end{tabular}


Table 2 Item parameters, fit statistics, local dependence, and DIF results for the 51 PROMIS $^{\oplus}$ depression items (Continued)

\begin{tabular}{|c|c|c|c|c|c|c|c|c|c|c|c|}
\hline \multirow[t]{2}{*}{$\#$} & \multirow[t]{2}{*}{ Item Stem } & \multicolumn{5}{|c|}{ Item Parameters } & \multicolumn{2}{|c|}{ Item Fit } & \multirow[b]{2}{*}{ LD } & \multicolumn{2}{|c|}{$b$-DIF } \\
\hline & & $a$ & $b_{1}$ & $b_{2}$ & $b_{3}$ & $b_{4}$ & $S-X^{2}$ & d.f. & & $\overline{x^{2}}$ & d.f. \\
\hline 44 & I felt that I had no energy & 1.99 & -0.81 & 0.15 & 1.20 & 2.39 & 192.4 & 182 & 41,43 & & \\
\hline 45 & I had crying spells & 1.99 & 0.83 & 1.49 & 2.34 & 3.33 & 122.0 & 109 & 34 & 34.7 & 4 \\
\hline 46 & I reacted slowly to things that were done or said & 1.9 & -0.18 & 0.93 & 2.3 & 3.3 & 160.8 & 143 & 40 & & \\
\hline 47 & I was unable to do many of my usual activities & 1.8 & 0.18 & 1.08 & 2.2 & 3.6 & 193.7 & 146 & & & \\
\hline 48 & I had little desire to eat & 1.48 & 0.29 & 1.39 & 2.70 & 3.86 & 175.3 & 151 & & & \\
\hline 49 & I disliked the way my body looked & 1.39 & -1.07 & -0.31 & 0.87 & 1.82 & 299.4 & 217 & & 76.4 & 4 \\
\hline 50 & I ate more than usual & 1.19 & -0.54 & 0.70 & 2.33 & 3.73 & 227.8 & 180 & & & \\
\hline 51 & I lost weight without trying & 0.57 & 1.90 & 4.24 & 7.03 & 9.39 & 151.8 & 124 & & & \\
\hline
\end{tabular}

Note. Italicized $\boldsymbol{S}-\boldsymbol{X}^{\mathbf{2}}$ and $\boldsymbol{X}^{\mathbf{2}}$ values are significant at $p<0.01$ after Benjamini-Hochberg correction for multiplicity $L D$ Local dependence detected with indicated item numbers

The current calibrations are provided for didactic purposes and are not intended to replace the official PROMIS ${ }^{\oplus}$ parameters or to be used for research

respond differently to items (after controlling for the latent trait level). For instance, the presence of DIF for a depression item may indicate reduced validity for between-group comparisons, because responses may reflect individual-level characteristics rather than the depression trait that the PRO is intended to measure.

There are two types of DIF: uniform and non-uniform. Uniform DIF occurs when an item is consistently more likely to be endorsed by one subgroup across all levels of the latent trait. Uniform DIF is detected when one subgroup has higher difficulty/severity parameters $\left(b_{i j}\right.$ parameters) than another subgroup. In non-uniform DIF, the strength of the association (as measured by the $a$ parameter [discrimination parameter]) between the item and the underlying trait differs by sub-group. In this paper, our example focuses on a didactic example of detecting DIF (uniform or non-uniform) for gender in depression items because there is evidence that women experience some depression symptoms differently than men $[55,56]$.

There are a variety of ways to assess DIF, such as Mantel-Haenszel, IRT-based methods, and ordinal logistic regression. For example, in several PROMIS ${ }^{\circ}$ item banks, logistic ordinal regression (e.g., lordif in $\mathrm{R}$ [57]) was used. Scott and colleagues [58] and Crane and colleagues $[59,60]$ provide overviews of using logistic regression techniques to detect DIF in quality of life scales. There have also been developments in hybrid IRT/ordinal logistic regression models (e.g., [61]). After detecting DIF via statistical methods, we recommend consulting content experts to determine if there is a substantive justification for DIF or if it is more likely to be statistical noise.

In the current paper, DIF for gender was tested using Wald $x^{2}$ to evaluate statistical significance at the 0.01 level (see Fig. 2). We did not pre-select anchor items, and thus all items were used to estimate the depression mean and standard deviation separately for men and women. These estimates were then fixed, and all item parameters were estimated separately for men and women.

To control the type I error rate, we used an omnibus Wald $X^{2}$ statistic prior to examining individual items. For each item, an omnibus Wald $\chi^{2}$ statistic was computed to test for overall DIF. The supplemented EM algorithm was used to estimate more accurate standard errors to support the Wald test [62]. If the total $\mathrm{x}^{2}$ was significant, the individual $a$ and $b$ parameter DIF statistics were computed using constrained tests. If significant DIF was detected based on $p<0.01$ [63], an iterative process set the non-flagged items as the anchors and the Wald $X 2$ statistic was recomputed to correct for Type 1 error [64]. Following the iterative procedure, the magnitude of DIF was evaluated graphically by examining the item characteristic curves [65]. See papers by Thissen and colleagues [66] and Chen and colleagues [67] for discussions of alternative methods for controlling the type I error rate.

We used IRTPRO to plot ICCs for men and women on the same graph. We inspected the curves to see if they were similarly steep for women and men (indicating how related the item is to the latent trait) and whether the curves were in a similar place along the depression continuum. If $b$-DIF is present, we would expect to see one gender consistently endorsing higher levels of depression.

\section{Results \\ Sample}

The PROMIS Wave 1 cohort has been described elsewhere $[12,23]$. See the introductory paper in this series for a demographics table [68]. A sample of 925 individuals completed the computerized PROMIS depression items and 11 demographic items. One-hundred individuals were deleted because they had a mean response time of less than $1 \mathrm{~s}$ or 10 or more items in a row where response time was less than $1 \mathrm{~s}$. The final sample size 
was 825 individuals, one of whom did not report a gender. Gender was equally distributed (49\% male, 51\% female) and the mean age was 50.9 years $(\mathrm{SD}=18.9)$.

\section{Missing data}

IRT uses all available information, and thus listwise deletion is unnecessary. However, little missing data was noted. Less than five responses were missing for demographic items. Missing data for the depression items ranged from 40 respondents (5\%) for the items "I felt worthless" and "I felt ignored by other people" to 46 respondents (6\%) for the items "I felt guilty" and "I was unable to do many of my usual activities." In concordance with missing data standards, multiple imputation was not used [69, 70].

Imputation estimates what a missing value might have been based on sources of information such as nonmissing observations in the dataset and demographic characteristics. See [69-71] for a discussion of handling missing data in PRO measures, including when and how to use multiple imputation. Specific to IRT models, Finch [71] found that multiple imputation produced the least bias for producing accurate estimates of item difficulty and discrimination parameters.

\section{Item misfit (51 original items)}

Table 2 lists the $S-X^{2}$ item misfit statistics. Out of 51 depression items, 9 items (18\%) exhibited misfit after the Benjamini-Hochberg correction for multiplicity. Items exhibiting misfit were reviewed with content experts. They recommended setting aside the following 5 misfit items because they likely tap into constructs beyond depression: "ate more than usual," "disliked the way my body looked," "disappointed in myself," "unable to do many of my usual activities," and "felt slowed down." One item was recommended to be set aside because it was likely to exhibit floor effects and the item also assumed recognition of depression symptoms from respondents: "I felt like I needed help for my depression." Three items were judged by content experts to be integral pieces of depression, and thus were recommended to retain unless further psychometric problems were identified: "sad," "depressed," and "wished I were dead and away from it all."

\section{Local independence (51 original items)}

Four sets of items (14 items in total [27\%]) were found to be locally dependent (Table 2), including fatigue, suicidal ideation, crying, and cognition. The subdomain with the most locally dependent items was suicidal ideation: "wished I were dead and away from it all," "thought about suicide," "no reason for living," and "others would be better off if I were dead." . For each set of locally dependent items, the best performing item was identified (usually the item with the best discrimination parameter) and then reviewed with content experts. Content experts recommended the following items to be retained from the LD sets: "I felt I had no reason for living," "I reacted slowly to things that were done or said," and "I had trouble making decisions." For fatigue, content experts recommended keeping the item, "everything is an effort" over items assessing lack of energy because it was perceived to be more related to cognitive aspects of depression. No items assessing crying were retained because they also demonstrated DIF for gender (see below).

\section{Differential item functioning (51 original items)}

Significant Wald $X^{2}$ statistics for DIF by gender are presented in Table 2 . When depression level was held constant, 3 items (6\%) exhibited significant gender DIF. In all cases, the type of DIF detected was in the threshold $(b)$ parameters (i.e., uniform DIF), indicating that women were more likely than men to endorse these depression items at all response levels. The items exhibiting DIF for gender included: "crying spells," "felt like crying," and "disliked the way my body looked."

DIF was also examined graphically using item characteristic curves. Figure 3 shows an example of gender $b$-DIF. For this item, the item characteristic curves for each response category are similarly steep across gender, indicating that the items are equally discriminating, or related to depression, for both men and women. However, the item characteristic curves are shifted to the right for men, indicating that men needed a higher level of experienced depression to endorse response options than women.

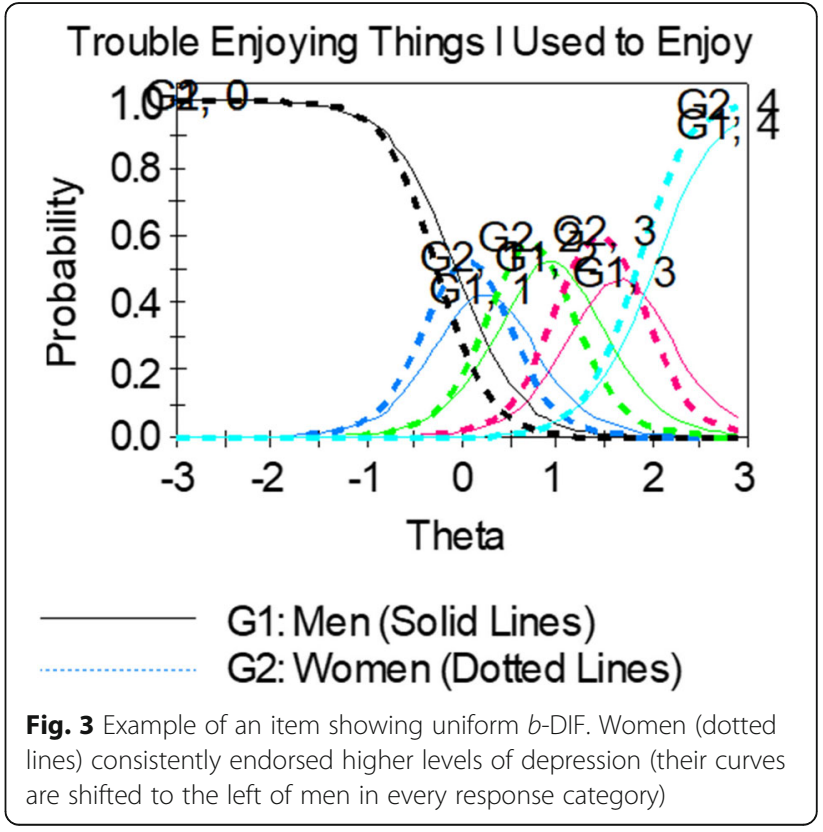


Content experts perceived there was substantive justification for differential performance of crying items between men and women and recommended setting them aside. The general guidance is to remove items showing DIF from the item bank as long as content validity is not impacted. However, if the decision is made to retain an item exhibiting DIF for content considerations, then additional analysis steps should be taken to examine the impact on overall scores if DIF is ignored. See [72-74] for guidance on additional analysis steps. A less preferred option is to calculate different item parameters for men and women. As item banks like those from PROMIS are expected to evolve over time, the logistics for maintaining separate item parameters may become quite complex. This complexity should be weighed in the decision to use separate item calibrations for groups to control for DIF in the scores.

\section{Selecting items for short forms}

Table 2 shows the 51 items in descending order from highest to lowest discriminating items ( $a$ parameter). To accommodate DSM-V criteria in short form 1, we made trade-offs between precision and content validity based on consensus discussions between psychometricians and content experts.

Table 3 shows the items selected for short forms 1 and 2. The most discriminating item in the bank of 51 items was "I felt hopeless," which also met DSM-V criteria for symptoms and did not exhibit LD or DIF, and thus was included on both short forms. To meet DSM-V criteria for depressed mood, we looked at items with the best psychometric properties that assessed mood. The item "felt depressed" discriminated highly but exhibited item misfit, and thus we included "unhappy" on short form 1 and "depressed" on short form 2. The DSM-V mood criterion also includes diminished interest or pleasure in activities, and thus we included the item, "I had trouble enjoying the things I used to enjoy" on short form 1 and "I felt I had nothing to look forward to" on short form 2.

Next we looked at well performing items that could meet DSM-V criteria for the symptoms category

Table 3 Comparison of two potential short forms selected through a combination of psychometric properties and content validity considerations

\begin{tabular}{|c|c|c|c|c|c|}
\hline DSM-V Criterion & Item & Short Form 1 & $\begin{array}{l}\text { Short Form } 1 \\
\text { Rank Order } \\
\text { a-parameter } \\
\text { (based on } 51 \text { items) }\end{array}$ & $\begin{array}{l}\text { Short } \\
\text { Form } 2\end{array}$ & $\begin{array}{l}\text { Short Form } 2 \\
\text { Rank Order } \\
a \text {-parameter } \\
\text { (based on } \\
51 \text { items) } \\
\end{array}$ \\
\hline \multirow[t]{2}{*}{ 1. Depressed mood most of day } & I felt unhappy & $x$ & 4 & $x$ & 4 \\
\hline & I felt depressed & & & $x$ & 3 \\
\hline \multirow[t]{2}{*}{ 2. Little interest or pleasure in doing things } & $\begin{array}{l}\text { I had trouble enjoying the things } \\
\text { I used to enjoy }\end{array}$ & $x$ & 18 & & \\
\hline & I felt I had nothing to look forward to & & & $x$ & 9 \\
\hline $\begin{array}{l}\text { 3. Symptoms: psychomotor retardation } \\
\text { or agitation }\end{array}$ & $\begin{array}{l}\text { I reacted slowly to things that were } \\
\text { done or said }\end{array}$ & $x$ & 46 & & \\
\hline \multicolumn{6}{|l|}{ 4. Symptoms: insomnia/ hypersomnia } \\
\hline 5. Symptoms: fatigue & I felt that everything I did was an effort & $x$ & 39 & & \\
\hline \multirow[t]{3}{*}{ 6. Symptoms: worthlessness } & I felt I was not as good as other people & $x$ & 24 & & \\
\hline & I felt worthless & & & $x$ & 2 \\
\hline & I felt like a failure & & & $x$ & 6 \\
\hline 7. Symptoms: excessive guilt & I felt guilty & $x$ & 37 & & \\
\hline $\begin{array}{l}\text { 8. Symptoms: diminished ability to } \\
\text { think/ concentrate or indecisiveness }\end{array}$ & I had trouble making decisions & $x$ & 26 & & \\
\hline \multirow[t]{2}{*}{ 9. Symptoms: suicidal ideation } & I felt I had no reason for living & $x$ & 13 & & \\
\hline & $\begin{array}{l}\text { I felt like I wanted to give up } \\
\text { on everything }\end{array}$ & & & $x$ & 8 \\
\hline $\begin{array}{l}\text { 10. Symptoms: significant weight gain or } \\
\text { loss/appetite loss }\end{array}$ & $\begin{array}{l}\text { - I had little desire to eat } \\
\text { - I ate more than usual } \\
\text { - I lost weight without trying }\end{array}$ & & & & \\
\hline \multirow[t]{2}{*}{ 11. Significant distress or impairment } & I felt that nothing could cheer me up & & & $x$ & 5 \\
\hline & I felt emotionally exhausted & & & $x$ & 11 \\
\hline Symptoms: hopeless & I felt hopeless & $x$ & 1 & $x$ & 1 \\
\hline Symptoms: helpless & I felt helpless & & & $x$ & 7 \\
\hline Symptoms: withdrew from others & I withdrew from others & $x$ & 25 & & \\
\hline
\end{tabular}


(insomnia/hypersomnia, psychomotor agitation or retardation, fatigue, worthlessness/excessive guilt, diminished ability to think/concentrate or indecisiveness, suicidal ideation, significant weight gain or loss/appetite loss). On short form 1, six items (out of ten) were chosen because they met DSM-V criteria even though they provided lower discrimination values than other items: "I reacted slowly to things that were done or said," "I felt that everything I did was an effort," "I felt I was not as good as other people," "I felt guilty," "I had trouble making decisions," and "I withdrew from others." The final DSM-V criterion is clinically significant distress or impairment in social, occupational, or other areas. On short form 2, two items were included: "I felt that nothing could cheer me up" and "I felt emotionally exhausted."

Two DSM-V criteria could not be captured on short forms. Insomnia/hypersomnia could not be captured because a separate PROMIS ${ }^{\circ}$ item bank was developed for sleep issues [75], and thus no items assessing sleep are included in the depression bank. The items assessing weight/appetite, "I had little desire to eat," "I ate more than usual" and "I lost weight without trying" had the lowest discrimination parameters (and the item "I ate more than usual" was also significant for misfit). Content validity experts were concerned that the weight/appetite items were influenced by circumstances other than depression (e.g., health conditions, dieting, holidays). In addition, the item "I lost weight without trying" uses a severity response scale ("not at all," "a little," "somewhat," "quite a bit," "very much") instead of a frequency scale like the other depression items, which may have contributed to misfit. Given the psychometric issues and content concerns, these items were not considered for short forms.

\section{Model fit}

\section{1 items}

Table 4 shows model fit statistics for all 51 PROMIS Depression items and two potential short forms. Overall model fit for the 51 items was relatively poor, indicating that local independence and DIF should be examined to determine if the item bank could be reduced to potentially improve model fit. Cronbach's alpha, a measure of internal consistency/reliability from classical test theory, was above the $\geq .90$ criterion (marginal reliability $=0.98$ ). Additional criteria such as the AIC, BIC, RMSEA, and $\mathrm{M}_{2}$ showed poor fit for the pool of 51 items. The AIC and BIC were both relatively high at $65,230.18$ and 66 , 432.60, respectively (criterion: lower is better fit). The RMSEA was 0.43 , which is much higher than the criterion of $\leq .05[48,49]$. Finally, $\mathrm{M}_{2}$ was significant at the $p<.0001$ level $(163,378.86[\mathrm{df}=1071]$ for 51 items, indicating poor model fit.

\section{Short forms}

Short forms 1-2 performed similarly based on model fit statistics, but short form 2 provided more item precision (Table 4). In both short forms, the AIC, BIC, and RMSEA were low and the model fit statistic was not significant (indicating acceptable model fit). Internal consistency, as measured by Cronbach's alpha, was high at 0.95 for both forms (and marginal reliability was high at 0.96 ). Nine out of 11 DSM-V diagnostic criteria were satisfied on short form 1 vs. five on short form 2 .

Figure 4 displays item characteristic curves and item information curves for short forms 1 and 2. These plots graphically display the information conveyed in the item parameters. The location of the item characteristic curves and information curves confirms that these items measure the middle to upper end of the depression continuum.

In Fig. 4a for short form 1, the items "reacted slowly" and "everything was an effort" had information curves (dotted lines) around the .2 to .3 range, indicating less information was being obtained from these items than the other items in the higher range from .5 to .9. On short form 1, the items "no reason for living" and "not as good as other people" had trace lines bunched together and problems where "worse" response options did not have a higher probability of being

Table 4 Model fit changes for short form selection

\begin{tabular}{llllllll}
\hline Model & $\begin{array}{l}\text { Cronbach's AIC } \\
\text { alpha }\end{array}$ & BIC & -2log likelihood & $\Delta$ in -2log likelihood & RMSEA & $M_{2}$ (df) \\
\hline 51 items & 0.983 & $65,230.18$ & $66,432.60$ & $64,720.18$ & - & 0.43 & $163,378.86(1071)^{* * *}$ \\
Short Form 1 Prioritizing Content (10 items) & 0.946 & $13,762.99$ & $14,234.40$ & $13,562.99$ & $51,157.19$ & 0.01 & $1469.53(1420)$ \\
Short Form 2 Prioritizing Precision (10 items) & 0.945 & $13,825.12$ & $14,296.54$ & $13,625.12$ & $51,095.06$ & 0.01 & $1513.90(1420)$ \\
\hline
\end{tabular}

Cronbach's alpha $=$ measure of internal consistency/reliability from Classical Test Theory (criterion: $\geq .90$ ).

AIC Akaike information criterion (criterion: the lower the number, the better the fit)

$B I C$ Bayesian information criterion (criterion: the lower the number, the better the fit)

-2log likelihood $=$ if models are nested, subtract at each step to see if step is significant

RMSEA Root mean square error of approximation (criterion: $\leq .05$ ).

$\mathrm{M}_{2}=$ model fit.

${ }^{* * *} p<.001$ (Note: a significant value for model fit indicates that the model does NOT fit well)

df Degrees of freedom. 


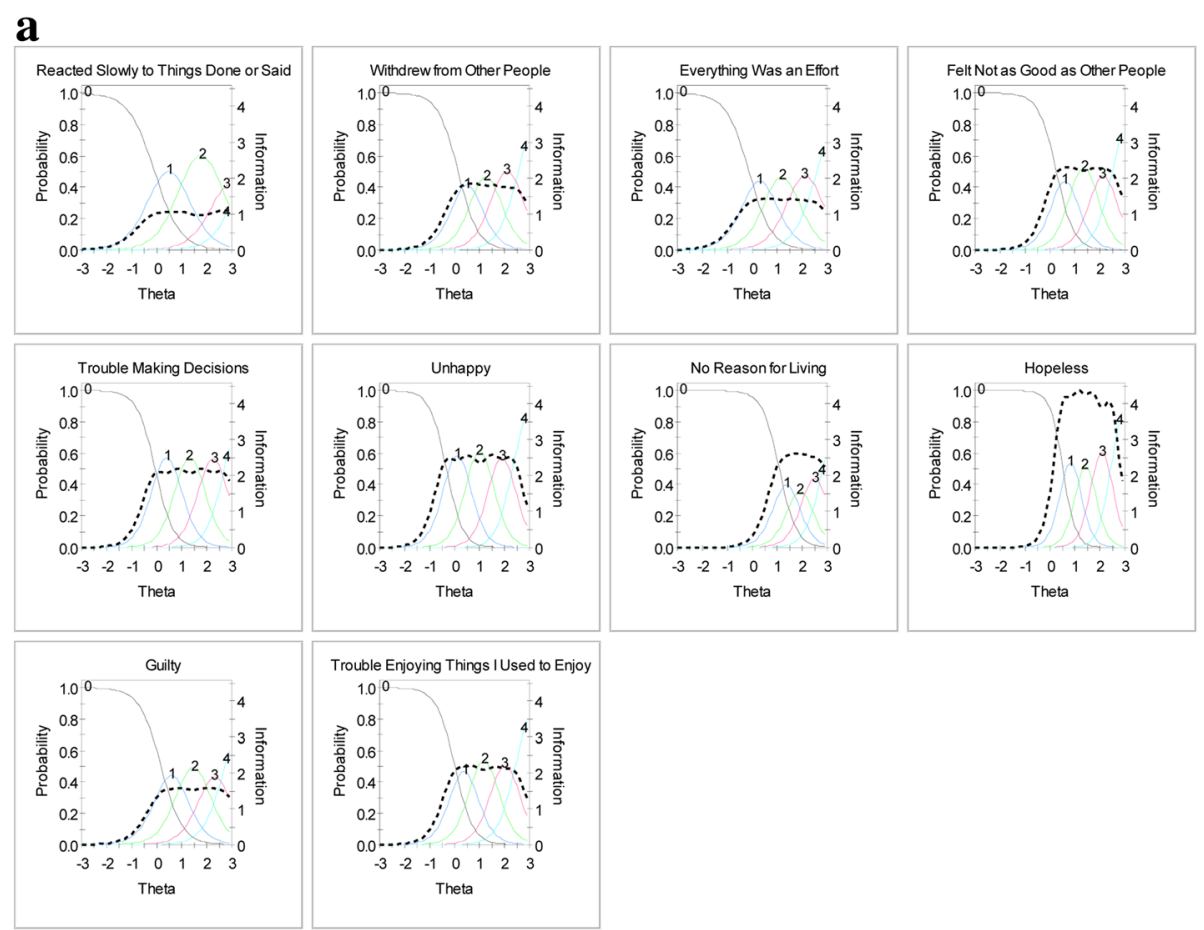

b

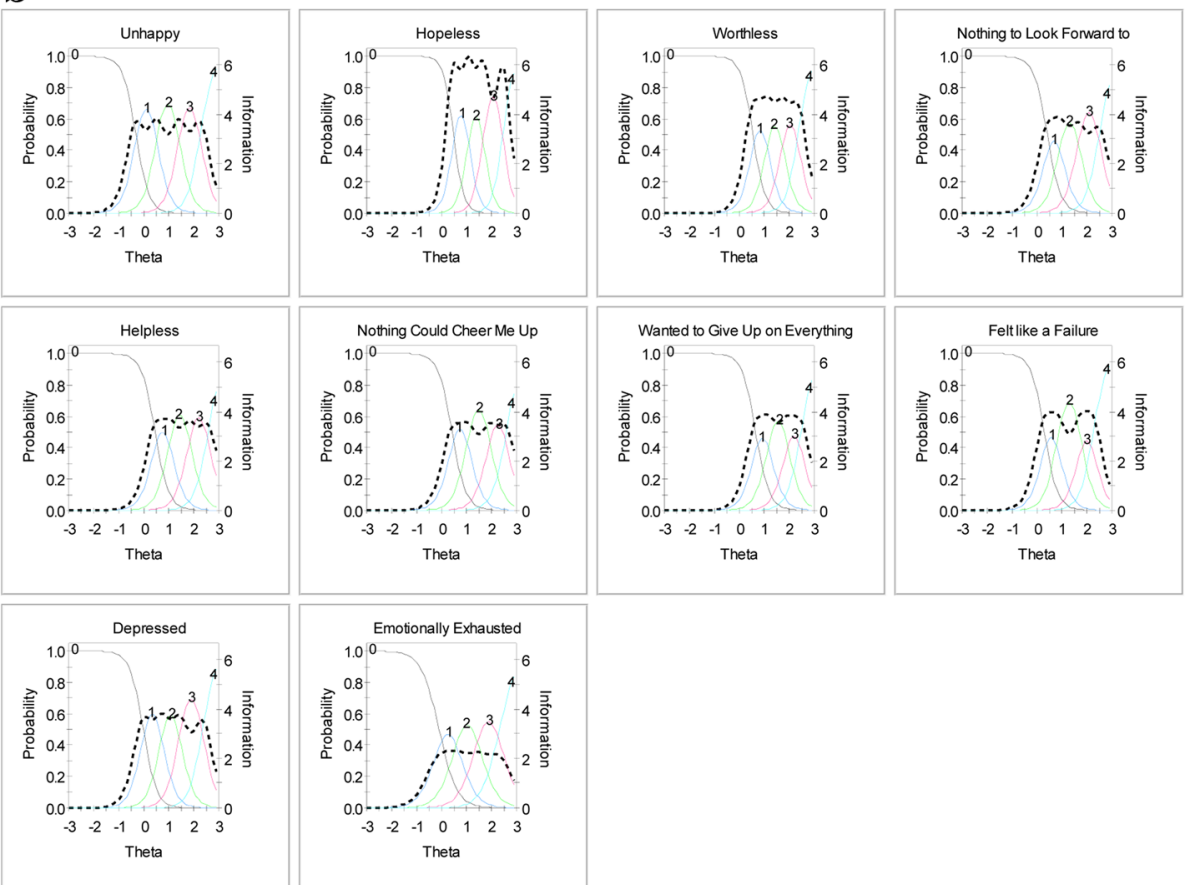

Fig. 4 Item characteristic curves and information curves for items in a Short Form 1 b Short Form 2. Solid lines: item characteristic curves; dotted lines: information curves

selected as depression level increased (i.e., did not increase monotonically).

In Fig. 4b for short form 2, the item "felt emotionally exhausted" had a lower information curve than other items. The items "helpless," "nothing could cheer me up," "wanted to give up on everything," and "felt like a failure" had trace lines bunched together and the probability for selecting response choices did not appear to increase monotonically as the level of depression increased. 
Figure 5 displays the test information curves for short forms 1 and 2. A reliability level of 0.90 corresponds approximately to a value of 10 on the information scale, and thus the short forms have adequate reliability for theta values of -0.5 and greater. In other words, the short forms measure depression well for people half a standard deviation below the mean depression score to the most depressed people at the upper end of the spectrum.

\section{Discussion}

We applied IRT modeling to the measurement of depression as part of a series of papers comparing different psychometric methodologies for evaluating PRO measures (IRT, classical test theory, and Rasch modeling). IRTPRO software [22] was used to examine model fit, local independence, and DIF of 51 depression items developed by the PROMIS initiative [23].

Of the original 51 depression items, less than 30\% exhibited problems such as local dependence (27\%), DIF between women and men (6\%), or item misfit (18\%), which is consistent with the original PROMIS findings
$[23,76]$. In selecting items for short forms, items that exhibited DIF, local dependence, or misfit were removed. The result was a more stable construct and improved model fit. Since local dependence and DIF are both indicative of multidimensionality, this finding highlights the importance of dimensionality considerations when fitting IRT models to PRO measures. See the corresponding paper in this series that describes scale-level analyses for assessing dimensionality in the classical test theory framework [33], such as confirmatory factor analysis.

In cases of DIF, subgroup bias was detected in the threshold parameters $(b)$ for 3 items ("I felt like crying," "I had crying spells," and "I disliked the way my body looked"). These items were removed from consideration for short forms in the current paper and the original developers also removed them from the official $\mathrm{PROMIS}^{\oplus}$ item bank containing the best performing 28 items [23].

In the current didactic exercise, two short forms consisting of 10 items were created using a combination of IRT methodology and DSM-V content considerations. Short form 1 prioritized content, and thus 6 items were
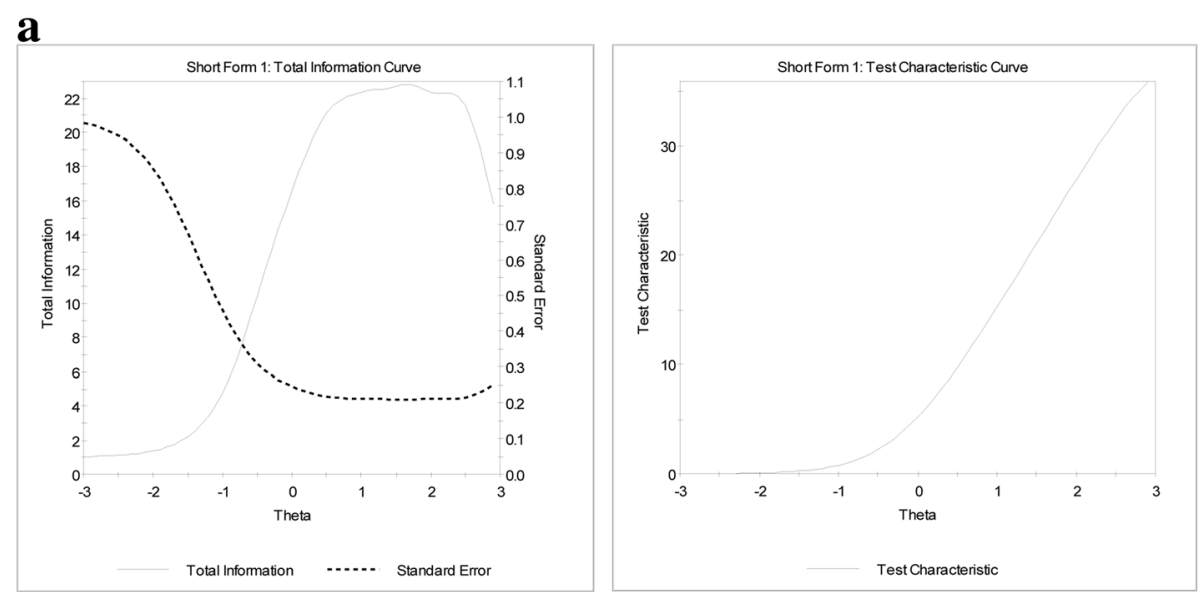

b
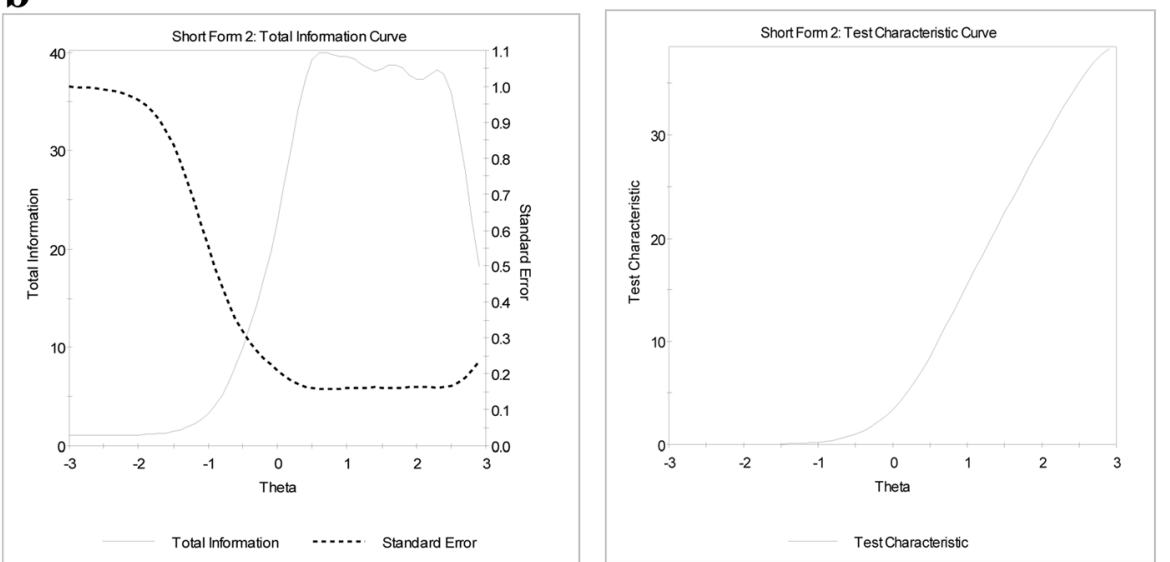

Fig. 5 Comparing test information curves for short forms 1 and 2. a Short Form 1 b Short Form 2 
included because they met DSM-V criteria but were in the middle or bottom half for discrimination parameters. Short form 2 prioritized high performing items and provided greater precision overall, but fewer DSM-V diagnostic criteria were satisfied. Short forms 1-2 performed equivalently in terms of model fit statistics but short form 2 items had more precision.

Two DSM-V criteria could not be captured on the short forms: weight/appetite and insomnia/hypersomnia The items assessing weight/appetite, "I had little desire to eat," "I ate more than usual" and "I lost weight without trying," had the lowest discrimination parameters and content experts flagged them to be set aside because circumstances outside depression affect them, like dieting or a health condition. In addition, the item "I lost weight without trying" uses a severity response scale ("not at all," "a little," "somewhat," "quite a bit," "very much") instead of a frequency scale ("never," "rarely," "sometimes," "often," "always") like the other depression items, which may have contributed to misfit. Future research should examine the degree to which differing response options influence model fit when developing and evaluating PRO measures.

We purposively chose a different content criterion (DSM-V [25]) than the original PROMIS short form [23] that used affective and cognitive dimensions of depression. We broadened the target content validity criteria to mirror DSM-V criteria for depression, which meant considering content for cognitive and affective aspects of depression, somatic symptoms (psychomotor retardation), behavioral (social withdrawal), and suicidal ideation aspects of depression. Short form 1 emphasizing content captured 9/11 DSM-V criteria; short form 2 emphasizing item precision captured 5; and the earlier PROMIS short form [23] captured $4 / 11$ criteria We present one way to combine psychometric data and content considerations to create short forms, but best practice recommendations would be helpful for the field.

Both an earlier short form from the PROMIS group [23] and current short forms assess a depression range from the mean to about 3 standard deviations above the mean, indicating that "low" depression was not being captured well by the items in the short forms. "Low" depression may represent a different construct than moderate-high depression. For example, low depression may represent a "quasi-trait" or tap into personality characteristics, and thus multidimensionality may be introduced if it is included in item banks. It may also be that the items assessing "low" depression were tested in the current paper but had lower discrimination parameters and/or content validity concerns. Future research should better conceptualize what "low" depression is with people with lived experiences of depression. A better understanding of the entire continuum of depression may lead to interventions to prevent major depression and its negative impact on quality of life.

\section{Strengths and limitations of IRT in the development and evaluation of PRO measures}

IRT models are highly flexible tools that provide itemand measure-level data, and thus can overcome shortcomings of classical test theory that produces scale-level data. By using item- and test-level information provided by IRT models, the most efficient administration approach can be used to reduce response burden with a high level of information/reliability. Both IRT and Rasch models allow short forms to be compared because they adjust for the difficulty of items. IRT models also allow for adjustment for discrimination parameters (because the $a$-parameter is allowed to vary in IRT but is held constant in Rasch models).

IRT also offers the ability to test item bias across demographic or clinical subgroups with one of several DIF methods [57-61]. Identifying DIF is important because the presence of DIF in a scale can reduce validity and reliability in measuring the latent trait [17]. DIF was a key component of PROMIS ${ }^{\bullet}$ methodology to select the best performing items for calibrated item banks $[11,12,23]$. For the PROMIS ${ }^{\circ}$ Depression item bank, Pilkonis and colleagues [23] considered DIF evidence (due to age, race/ethnicity, and education) as part of a panel of psychometric analyses. In the current study, we narrowed it to DIF for gender to keep the didactic exercise manageable. Readers interested in a broader discussion of DIF and alternative uses (e.g., using DIF to develop separate scoring algorithms for subgroups exhibiting DIF) are referred to [54, 72-74].

Multiple software applications are available for IRT. Some choices for software applications include IRTPRO (see Fig. 2), PROC IRT in SAS, MPLUS, MULTILOG, PARSCALE, flexMIRT, and Xcalibre.

IRT models generally require a large sample size to obtain accurate and stable item parameters, which can be costly and time-consuming. As the number of response categories or the number of items increases, a larger sample size is needed due to the increase in the number of item parameters to be estimated. Items that have a modest relationship with the latent construct will also require a larger sample size since more information will be necessary to compensate.

The current study used a large sample, and thus the challenging issues of non-normal population distributions, substantial multidimensionality, longitudinal data, and small sample size are not addressed. Reise and colleagues [77] discuss alternative approaches to addressing non-normal distributions in IRT models. Issues of small size are tackled by Houts and colleagues [78] who describe the use of longitudinal IRT models as a 
pragmatic solution, and by Finch and French [79] who compare estimation methods for IRT models with small samples. See [80] for an overview of multidisciplinary IRT methods and [27] for a good discussion of a Bayesian multilevel multidimensional IRT model for locally dependent data. As the application of IRT to PRO measures continues to evolve, more research addressing these issues will be needed.

\section{Conclusions}

Item response theory (IRT) is a family of flexible statistical models providing both item- and scale-level information, making it a powerful tool for PRO measure construction and refinement. Combining psychometric data with stakeholder input (including people with lived experiences of the health condition and clinicians) is highly recommended for scale development and evaluation. An example application and software output were described to encourage PRO researchers to consider IRT methods in the aim for accurate, precise scores that are sensitive to change and comparable across studies and populations.

\section{Abbreviations \\ AIC: Akaike information criterion; BIC: Bayesian information criterion; CAT: Computerized adaptive testing; DIF: Differential item functioning; DSM-V: Diagnostic and statistical manual version 5; EORTC: European Organisation for Research and Treatment of Cancer; GRM: Graded response model; ICC: Item characteristic curve; IRT: Item response theory; LD: Local dependence; NIH: National Institutes of Health; PRO: Patient- reported outcome; PROMIS: Patient-reported outcomes measurement information system; RMSEA: Root mean square error of approximation}

\begin{abstract}
Acknowledgements
The authors would like to thank the Patient-Reported Outcomes Measurement Information System (PROMIS ${ }^{\oplus}$ ) group for making available the data on the PROMIS Depression Item Bank that was used for illustrative purposes in this paper. In addition, the authors thank SIG members for their review of an earlier version. The authors received writing and editorial support under the guidance of the authors from Drs Chad Green and Amlan RayChaudhury (Clinical Outcomes Solutions).
\end{abstract}

\section{Declaration}

This paper was reviewed and endorsed by the International Society for Quality of Life Research (ISOQOL) Board of Directors as an ISOQOL publication and does not reflect an endorsement of the ISOQOL membership. All statements, findings and conclusions in this publication are solely those of the authors and do not necessarily represent the views of ISOQOL.

\section{Authors' contributions}

Conception or design of the work; data analysis and interpretation; critical revision (all authors); manuscript preparation (AMS, LDM). All authors read and approved the final manuscript.

\section{Funding}

AS received funding from AHRQ (R25-CA116339, R25-CA057726, and T32-HS000032). All other none.

\section{Availability of data and materials}

The datasets supporting the conclusions of this article are available from the PROMIS Health Organization, http://www.healthmeasures.net/exploremeasurement-systems/promis. The calibrations and short forms presented in this series are not intended to replace official PROMIS ${ }^{\oplus}$ parameters.

\section{Ethics approval and consent to participate}

Use of a publicly available, de-identified data set, and thus IRB exemption was granted from the University of North Carolina at Chapel Hill.

\section{Consent for publication}

Not applicable.

\section{Competing interests}

The authors declare they have no competing interests.

\section{Author details}

'Department of Health Policy and Management, University of North Carolina at Chapel Hill, 1101-G McGavran-Greenberg Hall (CB\# 7411), Chapel Hill, NC 27599, USA. 'Lineberger Comprehensive Cancer Center, University of North Carolina at Chapel Hill School of Medicine, 101 Manning Drive, Chapel Hill, NC 27599, USA. ${ }^{3}$ RTI Health Solutions, 3040 Cornwallis Road, Research Triangle Park, NC 27709-2194, USA. ${ }^{4}$ Current affiliation: Medical Social Sciences; Feinberg School of Medicine, Northwestern University, $625 \mathrm{~N}$ Michigan Ave Suite 2700, Chicago, IL 60611, USA. ${ }^{5}$ Current affiliation: Center for Health Measurement Department of Population Health Sciences and Pediatrics, Duke University School of Medicine, 2200 West Main St, Suite 720A, Durham, NC 27707, USA.

Received: 4 February 2019 Accepted: 19 June 2019

Published online: 30 July 2019

\section{References}

1. U.S. Department of Health and Human Services. (2009). Guidance for industry. Patient-reported outcome measures: Use in medical development to support labeling claims. Bethesda: http://www.fda.gov/downloads/drugs/ guidancecomplianceregulatoryinformation/guidances/UCM193282.pdf. Accessed Apr 2019.

2. Dinan, M. A., Compton, K. L., Dhillon, J. K., Hammill, B. G., Dewitt, E. M., Weinfurt, K. P., \& Schulman, K. A. (2011). Use of patient-reported outcomes in randomized, double-blind, placebo-controlled clinical trials. Medical Care, 49(4), 415-419.

3. Kyte, D. G., Draper, H., Ives, J., Liles, C., Gheorghe, A., \& Calvert, M. (2013). Patient reported outcomes (PROs) in clinical trials: Is 'in-trial' guidance lacking? A systematic review. PLoS One, 8(4), e60684.

4. Brundage, M., Blazeby, J., Revicki, D., et al. (2013). Patient-reported outcomes in randomized clinical trials: Development of ISOQOL reporting standards. Quality of Life Research, 22, 116-1175.

5. Gnanasakthy, A., Mordin, M., \& Clark, M. (2012). A review of patientreported outcome labels in the United States: 2006 to 2010. Value in Health, 15, 437-442.

6. Turner, R. R., Quittner, A. L., \& Parasuraman, B. M. (2007). Patientreported outcomes: Instrument development and selection issuesSpecial Issue: The FDA Guidance for Patient-Reported Outcomes. Value in Health, 10(Supp 2), S86-593.

7. Yang, L. Y., Manhas, D. S., Howard, A. F., et al. (2018). Patient-reported outcome use in oncology: A systematic review of the impact on patientclinician communication. Support Care Cancer, 26, 41-60.

8. Chen, J., Ou, L., \& Hollis, S. J. (2013). A systematic review of the impact of routine collection of patient reported outcome measures on patients, providers and health organisations. BMC Health Services Research, 13, 211.

9. Kendrick T, El-Gohary M, Stuart B, Gilbody S, Churchill R, Aiken L, Bhattacharya A, et al (2016) Routine use of patient reported outcome measures (PROMs) for improving treatment of common mental health disorders in adults. Cochrane Database of Systematic Reviews 7: Art. No.: CD011119.

10. Etkind, S. N., Daveson, B. A., Kwok, W., et al. (2015). Capture, transfer, and feedback of patient-centered outcomes data in palliative care populations: Does it make a difference? A systematic review. Journal of Pain and Symptom Management, 49, 611-624.

11. Reeve, B. B., Hays, R. D., Bjorner, J. B., et al. (2007). Psychometric evaluation and calibration of health-related quality of life item banks: Plans for the patient-reported outcomes measurement information system (PROMIS $\left.{ }^{\oplus}\right)$. Medical Care, 45, S22-S31.

12. Cella, D., Yount, S., Rothrock, N., Gershon, R., Cook, K., Reeve, B., et al. (2007). The patient reported outcomes measurement information system 
(PROMIS ${ }^{\oplus)}$ : Progress of an $\mathrm{NIH}$ roadmap cooperative group during its first two years. Medical Care, 45, S3-S11.

13. Cull, A. (1993). Organization and achievement of the EORTC quality of life study group. Quality of Life Research, 2, 63.

14. Aaronson, N. K., Ahmedzai, S., Bergman, B., Bullinger, M., Cull, A., Duez, N. J., et al. (1993). QLQ-C30: A quality-of-life instrument for use in international clinical trials in oncology. Journal of the National Cancer Institute, 85, 365-376.

15. Orlando Edelen, M., \& Reeve, B. B. (2007). Applying item response theory (IRT) modeling to questionnaire development, evaluation, and refinement. Quality of Life Research, 16, 5-18.

16. Reise, S. P., Ainsworth, A. T., \& Haviland, M. G. (2005). Item response theory: Fundamentals, applications, and PROMIS in psychological research. Current Directions in Psychological Science, 14, 95-101.

17. van der Linden, W., \& Hambleton, R. K. (Eds.). (1997). Handbook of modern item response theory. New York: Springer.

18. Hambleton, R. K. (2000). Emergence of item response modeling in instrument development and data analysis. Medical Care, 38(supplement 2), 60-65.

19. Hays, R. D., Morales, L. S., \& Reise, S. P. (2000). Item response theory and health outcomes in the 21st century. Medical Care, 38(Supplement 2), 28-42.

20. Chang, C.-H., \& Reeve, B. B. (2005). Item response theory and its applications to patient-reported outcomes measurement. Evaluation \& the Health Professions, 28, 264-282.

21. Bjorner, J. B. (2019). State of the psychometric methods: Comments on the ISOQOL SIG psychometric papers. Journal Patient Reported Outcomes, https://doi.org/10.1186/s41687-019-0134-1.

22. Cai, L., Thissen, D., \& du Toit, S. H. C. (2011). IRTPRO for windows [computer software]. Lincolnwood: Scientific Software International.

23. Pilkonis, P. A., Choi, S. W., Reise, S. P., Stover, A. M., Riley, W. T., \& Cella, D. (2011). Item banks for measuring emotional distress from the patientreported outcomes measurement information system (PROMIS ${ }^{\oplus}$ ): Depression, anxiety, \& anger. Assessment, 18, 263-283.

24. Pilkonis, P. A., Yu, L., Dodds, N. E., Johnston, K. L., Maihoefer, C. C., \& Lawrence, S. M. (2014). Validation of the depression item bank from the patient-reported outcomes measurement information system (PROMIS ${ }^{\oplus}$ ) in a three-month observational study. Journal of Psychiatric Research, 56, 112-119.

25. American Psychological Association. (2013). Diagnostic and statistical manual (5th ed.). Washington, D.C.: author.

26. Cai, L., Choi, K., \& Harrell, L. (2016). Item response theory. Annual Review Statistic Application, 3, 297-321.

27. Fujimoto, K. A. (2018). A general Bayesian multilevel multidimensional IRT model for locally dependent data. Mathematical and Statistical Psychology, 71, 536-560.

28. Samejima, F. (1969). Estimation of latent ability using a response pattern of graded scores (Psychometric Monograph No. 17). Richmond: Psychometric Society. Retrieved from: http:/www.psychometrika.org/journal/online/MN17. pdf. Accessed 28 June 2019.

29. Samejima, F. (1997). Graded response model. In van der Linden WJ \& R. K. Hambleton (Eds.), Handbook of modern item response theory. New York: Springer.

30. Lazarsfeld PF (1950) The logical and mathematical foundation of latent structure analysis. In S.A. Stouffer, L. Guttman, E.A. Suchman, P.F. Lazarsfeld, S.A. Star, J.A. Clausen. Measurement and prediction (pp. 362-412). Princeton University Press, Princeton.

31. Birnbaum, A. (1968). Some latent trait models and their use in inferring an examinee's ability. In F. M. Lord \& M. R. Novick (Eds.), Statistical theories of mental test scores (pp. 392-479). Reading: Addison-Wesley.

32. Fan, X. (1998). Item response theory and classical test theory: An empirical comparison of their item/person statistics. Educational and Psychological Measurement, 58, 357-381.

33. Nolte, S., Coon, C., Hudgens, S., et al. (2019). Psychometric evaluation of the PROMIS depression item bank: An illustration of classical test theory methods. Journal Patient Reported Outcomes, https://doi.org/10.1186/s41687-019-0127-0.

34. Klem, M. L., Saghafi, E., Abromitis, R., Stover, A., Dew, M. A., \& Pilkonis, P. A. (2009). Building PROMIS ${ }^{\oplus}$ item banks: Librarians as co-investigators. Quality of Life Research, 18, 881-888.

35. Kelly, M. A. R., Morse, J. Q., Stover, A., Hofkens, T., Huisman, E., Eisen, S., et al. (2011). Describing depression: Where patient experiences and clinical definitions overlap. British Journal Clinical Psychology, 50, 46-66.

36. DeWalt, D. A., Rothrock, N., Yount, S., Stone, A. A., \& on behalf of the PROMIS ${ }^{\circledR}$ Cooperative Group. (2007). Evaluation of item candidates: The PROMIS qualitative item review. Medical Care, 45, S12-S21.
37. Thissen, D. (1982). Maximum marginal likelihood estimation for the oneparameter logistic model. Psychometrika, 47, 201-214.

38. Muraki, E. (1992). A generalized partial credit model: Application of an EM algorithm. Applied Psychological Measurement, 16, 159-176.

39. Muraki, E. (1997). A generalized partial credit model. In van der Linden W \& R. K. Hambleton (Eds.), Handbook of modern item response theory (pp. 153164). New York: Springer.

40. Bock, R. D. (1972). Estimating item parameters and latent ability when responses are scored in two or more nominal categories. Psychometrika, 37, 29-51.

41. Bock, R. D., \& Mislevy, R. J. (1982). Adaptive EAP estimation of ability in a microcomputer environment. Applied Psychological Measurement, $6,431-444$.

42. Maydeu-Olivares, A. (2013). Goodness-of-fit assessment of item response theory models. Measurement: Interdisciplinary Res Perspectives, 11(3), 71-101.

43. Maydeu-Olivares, A., \& Joe, H. (2005). Limited and full information estimation and testing in 2nd contingency tables: A unified framework. Journal of the American Statistical Association, 100, 1009-1020.

44. Olivares, A., \& Joe, H. (2006). Limited information goodness-of-fit testing in multidimensional contingency tables. Psychometrika, 71, 713-732.

45. Akaike, H. (1974). A new look at the statistical model identification. IEEE Transactions on Automatic Control, 19, 716-723.

46. Schwartz, G. E. (1978). Estimating the dimension of a model. Annals of Statistics, 6, 461-464

47. Stone, C., \& Zhang, B. (2003). Assessing goodness of fit of item response theory models: A comparison of traditional and alternative procedures. Journal of Educational Measurement, 40(4), 331-352.

48. Cai, L., \& Monroe, S. (2013). IRT model fit evaluation from theory to practice: Progress and some unanswered questions. Measurement, 11, 102-106.

49. Orlando, M., \& Thissen, D. (2003). Further investigation of the performance of S-X2: An item fit index for use with dichotomous item response theory models. Applied Psychological Measurement, 27, 289-298.

50. Orlando, M., \& Thissen, D. (2000). Likelihood-based item fit indices for dichotomous item response theory models. Applied Psychological Measurement, 24, 50-64.

51. Benjamini, Y., \& Hochberg, Y. (1995). Controlling the false discovery rate: A practical and powerful approach to multiple testing. Journal Royal Statistic Society, 57, 289-300

52. Williams, V. S. L. Jones, L. V. \& Tukey, J. W. (1999). Controlling error in multiple comparisons, with examples from state-to-state differences in educational achievement. Journal of Educational and Behavioral Statistics, 24, 42-69

53. Chen, W.-H., \& Thissen, D. (1997). Local dependence indices for item pairs using item response theory. Journal of Educational and Behavioral Statistics, 22, 265-289

54. Thissen, D., Steinberg, L., \& Wainer, H. (1993). Detection of differential item functioning using the parameters of item response models. In P. W. Holland \& H. Wainer (Eds.), Differential item functioning (pp. 67-113). Hillsdale: Lawrence Erlbaum Associates.

55. Piccinelli, M., \& Wilkinson, G. (2000). Gender differences in depression: Critical review. British Journal Psychiatry, 177, 486-492.

56. Culbertson, F. M. (1997). Depression and gender: An international review. The American Psychologist, 52, 25-31.

57. Choi, S. W., Gibbons, L. E., \& Crane, P. K. (2011). Lordif: An R package for detecting differential item functioning using iterative hybrid ordinal logistic regression/item response theory and Monte Carlo simulations. Journal of Statistical Software, 39(8), 1-30.

58. Scott, N. W., Fayers, P. M. Aaronson, N. K., et al. (2010). Differential item functioning (DIF) analyses of health-related quality of life instruments using logistic regression. Health and Quality of Life Outcomes, 8, 81.

59. Crane, P. K., Gibbons, L. E., Ocepek-Welikson, K., Cook, K., \& Cella, D. (2007). A comparison of three sets of criteria for determining the presence of differential item functioning using ordinal logistic regression. Quality of Life Research, 16(Supp 1), 69-84.

60. Crane, P. K., Gibbons, L. E., \& Jolley, L. (2006). Differential item functioning analysis with ordinal logistic regression techniques: DIFdetect and difwithpar. Medical Care, 44(Suppl 3), S115-S123.

61. Mukherjee, S., Gibbons, L. E., Kristjansson, E., \& Crane, P. K. (2013). Extension of an iterative hybrid ordinal logistic regression/item response theory approach to detect and account for differential item functioning in longitudinal data. Psychological Test and Assessment Modeling, 55(2), 127-147. 
62. Langer, M. (2008). A reexamination of Lord's Wald test for differential item functioning using item response theory and modern error estimation (doctoral dissertation). Chapel Hill: University of North Carolina. Available from: https:// pdfs.semanticscholar.org/204e/a4e24df2284f4c6833b73ec18a01964fe2ca.pdf. Accessed 28 June 2019.

63. Cao, M., Tay, L., \& Liu, Y. (2016). A Monte Carlo study of an iterative Wald test procedure for DIF analysis. Educational and Psychological Measurement, 77, 104-118.

64. Woods, C. M., Cai, L., \& Wang, M. (2013). The Langer-improved Wald test for DIF testing with multiple groups: Evaluation and comparison to two-group IRT. Educational and Psychological Measurement, 73, 532-547.

65. Holland, P. W., \& Thayer, D. T. (1988). Differential item performance and the Mantel-Haenszel procedure. In H. Wainer \& H. I. Braun (Eds.), Test validity (pp. 129-145). Hillsdale: Lawrence Erlbaum Associates.

66. Thissen, D., Steinberg, L., \& Kuang, D. (2002). Quick and easy implementation of the Benjamini-Hochberg procedure for controlling the false positive rate in multiple comparisons. Journal of Educational and Behavioral Statistics, 27(1), 77-83.

67. Chen, J.-H., Chen, C.-T., \& Shih, C.-L. (2014). Improving the control of type I error rate in assessing differential item functioning for hierarchical generalized linear model when impact is presented. Applied Psychological Measurement, 38(1), 78-36.

68. Patrick, D. (2019). Many ways to skin a cat: Psychometric methods options illustrated. Journal Patient-Reported Outcomes, https://doi.org/10.1186/ s41687-019-0133-2.

69. Enders, C. K. (2010). Applied missing data analysis. New York: Guilford Press.

70. Fox-Wasylyshyn, S. M., \& Maher, M. E. (2005). Focus on research methods: Handling missing data in self-report measures. Research in Nursing \& Health, 28, 488-495.

71. Finch, H. (2008). Estimation of item response theory parameters in the presence of missing data. Journal of Educational Measurement, 45(3), 225-245.

72. Teresi, J. A., Ramirez, M., Lai, J.-S., \& Silver, S. (2008). Occurrences and sources of differential item functioning (DIF) in patient-reported outcome measures: Description of DIF methods, and review of measures of depression, quality of life and general health. Psychology Science Quarterly, 50, 538.

73. Teresi, J. A., Ramirez, M., Jones, R. N., et al. (2012). Modifying measures based on differential item functioning (DIF) impact analyses. Journal of Aging and Health, 24, 1044-1076.

74. Kleinman, M., \& Teresi, J. A. (2016). Differential item functioning magnitude and impact measures from item response theory models. Psychological Test and Assessment Modeling, 58(1), 79-98.

75. Buysse, D. J., Yu, L., Moul, D. E., Germain, A., Stover, A., Dodds, N. E., et al. (2010). Development and validation of patient-reported outcome measures for sleep disturbance and sleep-related impairment. Sleep, 33, 781-792.

76. Choi, S. W., Reise, S. P., Pilkonis, P. A., Hays, R. D., \& Cella, D. (2010). Efficiency of static and computer adaptive short forms compared to full-length measures of depressive symptoms. Quality of Life Research, 19, 125-136.

77. Reise, S. P., Rodriguez, A., Spritzer, K. L., \& Hays, R. D. (2018). Alternative approaches to addressing non-normal distributions in the application of IRT models to personality measures. Journal of Personality Assessment, 100(4), 363-374

78. Houts, C. R., Morlock, R., Blum, S. I., Edwards, M. C., \& Wirth, R. J. (2018). Scale development with small samples: A new application of longitudinal item response theory. Quality of Life Research, 27(7), 1721-1734.

79. Finch, H., \& French, B. F. (2019). A comparison of estimation techniques for IRT models with small samples. Applied Measurement in Education, 32(2), 77-96.

80. Osteen, P. (2010). An introduction to using multidimensional item response theory to assess latent factor structures. Journal of the Society for Social Work and Research, 1(2), 66-82.

\section{Publisher's Note}

Springer Nature remains neutral with regard to jurisdictional claims in published maps and institutional affiliations.

\section{Submit your manuscript to a SpringerOpen ${ }^{\circ}$ journal and benefit from:}

- Convenient online submission

- Rigorous peer review

- Open access: articles freely available online

- High visibility within the field

- Retaining the copyright to your article

Submit your next manuscript at $\boldsymbol{\nabla}$ springeropen.com 